ISSN: 0213-2052 - eISSN: 2530-4100

DOI: https://doi.org/10.14201/shha202139253278

\title{
NOTAS SOBRE LA PRESENCIA DE AUGUSTO EN EL ITER AB EMERITA ASTVRICAM: ACERCA DE DOS MILIARIOS DE LA PROVINCIA LVSITANIA
}

\section{Some Notes on the Presence of Augustus on the Iter ab Emerita Asturicam: About two Lusitanian Milestones}

\author{
Enrique PAREDES MARTÍN ${ }^{1}$ \\ Universidad Complutense de Madrid - Archivo Epigráfico de Hispania \\ enripare@ucm.es
}

Fecha de recepción: 15-09-2020 Fecha de aceptación: 22-12-2020

ORCID: https://orcid.org/0000-0002-1347-9917

RESUMEN: Se ofrece un detallado estudio acerca de dos miliarios ya conocidos y procedentes, respectivamente, de las localidades de Ahigal y Coria (Cáceres, España). En el primer caso, nuestra reinterpretación nos lleva a descartar la atribución tiberiana que ha sido tradicionalmente propuesta para el miliario de Ahigal, señalando que en realidad nos hallamos ante un hito augusteo. En el segundo caso, tratamos de probar que, frente a las dudas expresadas por parte de ciertos investigadores, efectivamente

1. Este trabajo ha sido realizado gracias a las Ayudas UCM para contratos de Personal Investigador en Formación, Convocatoria 2017 CT17/17-CT18/17; y en el marco del Grupo de investigación UCM 930692 Ciudades Romanas. Vaya todo nuestro agradecimiento a M. ${ }^{a}$ del Rosario Hernando y a Sergio España Chamorro por la lectura de la primera versión de este trabajo y por las sugerencias ofrecidas al respecto, de la misma forma que también agradecemos a los revisores anónimos sus recomendaciones que, sin duda, han contribuido notablemente a mejorar este trabajo. 
nos hallamos ante un miliario de Augusto. En función de estas consideraciones, y proponiendo a modo de hipótesis la relación del miliario augusteo de Coria con el iter ab Emerita Asturicam, planteamos algunas ideas tratando de reevaluar el papel de Augusto en la comúnmente denominada Vía de la Plata.

Palabras clave: epigrafía viaria; Miliarios; Augusto; Lusitania; Vía de la Plata.

ABSTRACT: We offer a detailed study about two already known milestones coming respectively from the villages of Ahigal and Coria (Cáceres, Spain). In the first case, our reinterpretation implies to discard the Tiberian attribution that has traditionally been proposed for this milestone from Ahigal, and we will be able to determine that actually this piece is an Augustan milestone. In the second case, we try to prove, in the face of doubts due by some researchers, that the inscription clearly shows that we are in the presence of a milestone attributed to Augustus. Based on these considerations, and proposing the probable relation between this Augustan milestone from Coria and the iter ab Emerita Asturicam, we consider some ideas about the Augustan role and presencie in the so-called Vía de la Plata.

Keywords: Road epigraphy; Milestones; Augustus; Lusitania; Vía de la Plata.

En diciembre del año 2017 se celebró en el Museo Nacional de Arte Romano de Mérida un seminario internacional con el título Consideraciones sobre la fundación de Augusta Emerita. Y algo más recientemente, las distintas aportaciones ofrecidas en este seminario sobre algunos de los aspectos más relevantes de los primeros años de la colonia emeritense han visto la luz bajo la forma de una monografía ${ }^{1}$. Especial atención nos merece, para el caso de lo aquí tratado, la contribución del profesor Mantas acerca del sistema viario lusitano en época augustea, contribución que recoge un pequeño corpus acerca de los - por otra parte escasos- miliarios de Augusto en la provincia Lusitania ${ }^{2}$. Nos referimos a los

1. Nogales Basarrate y Barrero Martín, La fundación.

2. Mantas, "A política". Tomando como base este trabajo, concordamos en lo general con el autor en su nómina de los miliarios augusteos lusitanos. Por nuestra parte, además, consideramos errónea la referencia de Roldán ("El camino», 22) a un miliario augusteo en las cercanías de la propia Mérida (sobre el cual, ciertamente, no contamos con ningún otro dato o referencia por mínima que sea), de la misma forma que hoy sabemos que el miliario del puente de Alconétar atribuido a Augusto por Torres y Tapia (Crónica, 366-367) en realidad se trataba de un hito de Tiberio, como ya recogiera Hübner en CIL II 4651 (pese a que, más recientemente, autores como Griñó Frontera, La Vía, 21, lo sigan considerando erróneamente como un miliario augusteo). 
hitos augusteos de Casar de Cáceres ${ }^{3}$, Fuenteguinaldo (Fig. 1) ${ }^{4}$ y Alfaiates (Fig. 2) ${ }^{5}$, así como al miliario de Coria, sobre cuyo carácter auténticamente augusteo volveremos más adelante. Vemos de este modo cómo el profesor Mantas prefiere excluir de este breve listado de miliarios augusteos lusitanos al, cuando menos, problemático hito de $\operatorname{Argomil}^{6}$ y al hito procedente de Moncarapacho (Fig. 3) ${ }^{7}$.

De modo paralelo, y en el marco de nuestro trabajo de revisión bibliográfica de cara a la elaboración del Corpus Miliariorum Lusitaniae (CML) actualmente en proceso de preparación, tuvimos la oportunidad de analizar la bibliografía relacionada con un miliario procedente de la localidad cacereña de Ahigal, tradicionalmente atribuido a Tiberio. Sin embargo, tal y como trataremos de mostrar en las páginas siguientes, creemos que no cabe duda de que esta pieza se trata en realidad de un nuevo miliario augusteo que, por tanto, ha de ser incluido desde ahora en el —aun

3. Roldán, Iter, 51, n. ${ }^{\circ} 25=$ CPILC $677=$ MVP $74=$ CILCC I $193=$ EDCS 43300051: Imp(erator) Caesar / Augustus / LIX.

4. HEp 2012, $419=$ AE 2012, $729=$ EDCS 67400282: CXX $/$ Imp (erator) $/$ Caesar $/$ divi f(ilius) / Augustus / co(n)s(ul) XI / imp(erator) X (recogemos aquí la lectura ofrecida en su edición original por Salinas y Palao, "Nuevo miliario", 274).

5. $A E$ 1967, $185=$ HEp 15, 2006, $505=$ HEPOL $20173=$ EDCS 09800141: CX[- - -] / Im[p(erator)] / Caesa[r] / divi f(ilius) / Augustus / c[o(n)]s(ul) XI / imp(erator) V[III?]. El carácter miliario de este hito, que ya planteara su editor original (Lambrino, "Les inscriptions, 14-17), ha sido defendido en fechas más recientes por Curado («Notas»), Saquete Chamizo ("Aspectos", 153), Mantas (As vias, 245 y 250; "Red viaria", 115; "A política», 206-208), Redentor y Carvalho ("Continuidade", 424-425) o Salinas ("El impacto", 611). Por su parte, Vaz ("Inscrição») u Osório (O povoamento, 86, 117-118 y 147-148, n. ${ }^{\circ} 37$ ) consideran que se trata de una inscripción honorífica.

6. HEp 1, 1989, $682=$ RAP $479=$ HEp 15, 2006, $502=$ HEPOL $22862=$ EDCS 22200364 : Imp(erator) / Caesar / divif(ilius) / Augustu[s] / co(n)s(ul) XI / imp(erator) VIII. Sumamente problemático, este hito de Argomil ha sido interpretado como miliario por autores como Curado ("Notas") o Redentor y Carvalho ("Continuidade», 424-425). Más cauto al respecto de esta identificación se muestra, en cambio, Mantas (As vias, 245 y 250; "Red viaria", 115; o - más explícitamente- Mantas, "A política", 208; "Da capital", 263) quien, al igual que Garcia (en RAP 479), Abascal Palazón («Programas", 53) o Perestrelo (A romanização, 136), plantea que, en realidad, se trata de una inscripción honorífica. Por su parte, autores como Alarcão (O domínio, 41) o Vaz ("Linhas», 394) creen que se trata de un terminus augustalis entre civitates no mencionadas.

7. IRCP $660=$ HEpOL 23866: - . - - - / Aug(usto) pon/tifici m/aximo m(ilia) p(assuum) $X$. Aunque tradicionalmente tenido por un miliario augusteo (así en IRCP 660; Encarnação, "Augusto e a Lusitânia", 204-205; o, en un primer momento, también Mantas, "As cidades", 184; "A cidade", 526; "As civitates", 299 y 304 n. 14), hoy día se tiende a considerar que se trataría, más bien, de un hito de época ya de Claudio: Mantas, "O espaço", 359 n. 17; As vias, 99; "A política», 211; o Salinas y Palao, «Nuevo miliario», 275-276. No obstante, vemos cómo aún, en fechas más recientes, Mantas ("A política», 211) considera que no resulta imposible atribuirlo realmente a Augusto. 


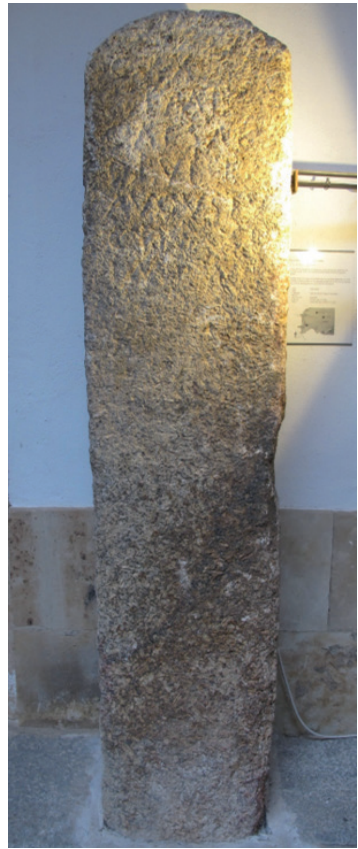

Fig. 1: Miliario de Fuenteguinaldo en el Museo de Salamanca (fotografía del autor).

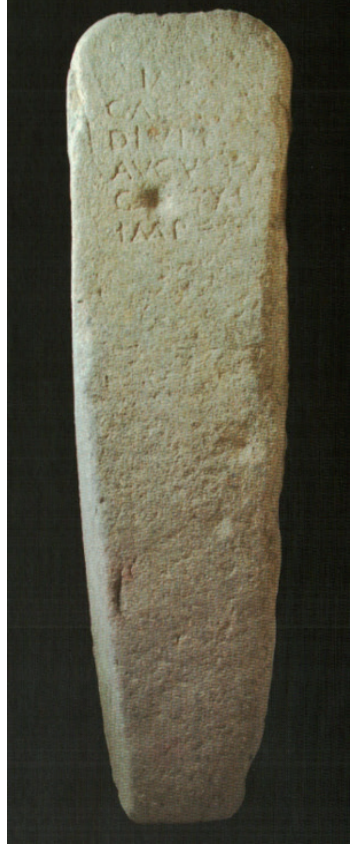

Fig. 2: Miliario de Alfaiates (fotografía tomada de Mantas, «Red viaria", 116, fig. 4).

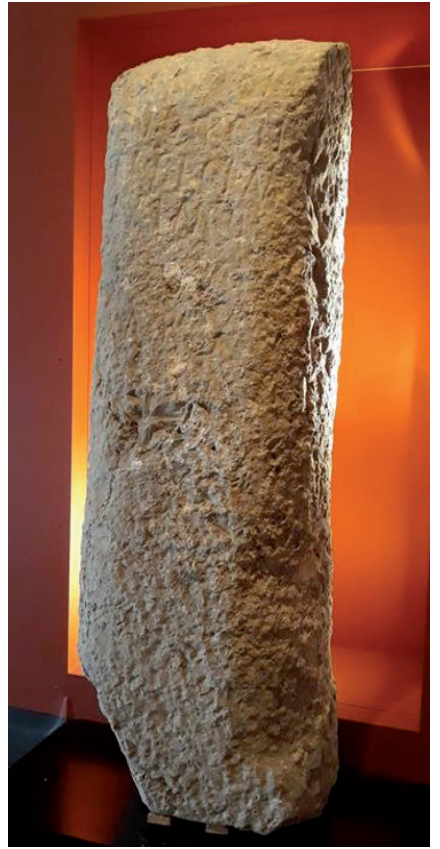

Fig. 3: Miliario de Moncarapacho en el Museu de Olhão (imagen tomada de https:// www.viasromanas.pt/vri/marco_de_bias.jpg, consultado el 11/09/2020).

así- limitado catálogo de miliarios lusitanos del que fuera el primer emperador romano y creador, en última instancia, de la propia Lusitania. La atribución de este miliario de Ahigal a Augusto, así como la confirmación de que el hito de Coria se trata igualmente de un miliario augusteo, nos permitirá reevaluar el papel de Augusto en la conformación viaria de la provincia lusitana.

1. El miliario itiberiano? de Ahigal (Figs. 4-6)

Procedencia y localización: El miliario se halló a comienzos del 2000 al realizar labores de limpieza en una finca, propiedad de D. Valentín Martín, situada al sur del término municipal de la localidad cacereña de Ahigal y junto a un tramo conservado aún hoy de la antigua calzada romana. 
Este lugar se corresponde con la milla CV que marca el miliario, por lo que se encontraría in situ. Tras su estudio, sus primeros editores procedieron a enterrarlo de nuevo en el mismo lugar (a tres metros y medio del bordillo izquierdo de la calzada romana en dirección a Cáparra) a fin de preservarlo de su expolio, siendo posteriormente desenterrado para realizar las fotografías (Figs. 4 y 5a) que, en el primer estudio de la pieza, no se pudieron efectuar. Desconocemos su localización actual, y, de hecho, Esteban Ortega lo da por desaparecido ${ }^{8}$. Por ello, nuestro análisis de esta pieza se ha realizado exclusivamente a través de las fotografías aportadas.

Soporte y estado de conservación: Se trata de un miliario de granito gris local (Fig. 4), que conserva completa la base cúbica y prácticamente la totalidad del fuste (ligeramente alisado en el frente epigráfico), que se halla fracturado en su parte superior. De hecho, en su primera edición de la pieza, Río-Miranda e Iglesias apuntan a la existencia de un "fragmento localizado a pocos metros del resto de la columna miliarian", de $12 \mathrm{~cm}$ de alto, que debía corresponder a su coronamiento. Aunque estos editores no apuntan a la presencia de texto en este fragmento superior (del que tampoco ofrecen fotografía), Gómez-Pantoja plantea la posibilidad de que en el miliario faltase una línea de texto por arriba, que ofrecería de esta forma una titulatura imperial más usual que la conservada ${ }^{10}$. También Esteban Ortega considera que esta fractura superior ha podido afectar al texto original, texto que, pese al aceptable estado de conservación general del soporte, se encuentra algo desgastado por la erosión ${ }^{11}$.

Medidas: $181 \mathrm{~cm}$ de altura (incluyendo el fragmento desprendido de su coronamiento) $\mathrm{x}$ 50 de diámetro ${ }^{12}$. La base cuadrangular presenta unos $52 \mathrm{~cm}$ de lado.

Notas paleográficas: Capitales cuadradas, con un ductus muy regular en lín. 1, pero de

8. Esteban Ortega (en CILCC III 920).

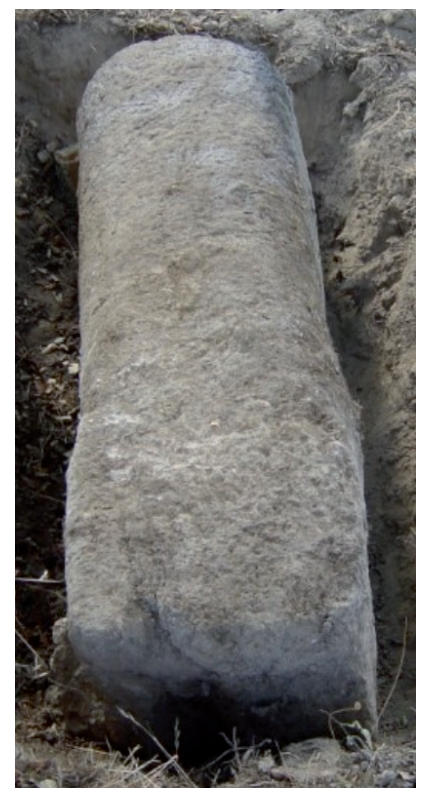

Fig. 4: Miliario de Ahigal en su lugar de hallazgo (fotografía de Río-Miranda e Iglesias, Ahigal, s. p.).

9. Río-Miranda e Iglesias, Boletín, 5

10. Gómez-Pantoja (en comentario a HEp 10, 2000, 108).

11. Esteban Ortega (en CILCC III 920).

12. Río-Miranda (en $C R C$ 16) ofrece unas dimensiones muy distintas para esta pieza: $240 \times 55 \mathrm{~cm}$. 
alturas un poco más irregulares en lín. 2. Altura letras: líns. 1-2: 5-6 cm; lín. 3: $7 \mathrm{~cm}$. Algunas letras $(V, F)$ conservan restos de los ápices. En lín. 2 se constatan dos interpunciones redondas ${ }^{13}$.

Referencias: Río-Miranda e Iglesias, Boletín, 5 = Río-Miranda, "Nuevas aportaciones", $4=$ HEp 10, 2000, 108 (con comentario de Gómez-Pantoja $)=$ Río-Miranda e Iglesias, Ahigal, s. p. = HEp 14, 2005, 78 (con comentario de Gómez-Pantoja $)=C R C 16=$ CILCC III $920=$ HEPOL $24064=$ EDCS 24500818 .

Texto y comentario:

Lectura de Río-Miranda e Iglesias, recogida también en HEp 14, CRC y CILCC III: Ti(berius) · Caesar / Divi · f(ilius) Augustus / CV.

Variante de lectura en lín. 2: Augusti (Río-Miranda, recogido en HEp 10).

No cabe duda de que nos hallamos ante un miliario de la milla CV del iter ab Emerita Asturicam. Más problemas ofrece, en cambio, la identificación del emperador bajo cuyo gobierno se erigió: los distintos editores que han tratado sobre este miliario han transmitido al principio de lín. 1 el nombre de Ti(berius), si bien en las fotografías de la pieza no parece observarse este nombre. La lectura inicial de Ti(berius), así como la lectura en genitivo de AVGVSTI en lín. 2, llevó a Río-Miranda a atribuir este miliario a Tiberio, idea en la que ha sido seguido más recientemente por Esteban Ortega ${ }^{14}$. Pero, al margen de que la forma correcta de esta pretendida filiación remitente a Augusto sería AVGVSTI F. y no F. AVGVSTI, como plantease el editor, lo cierto es que ya Gómez-Pantoja mostró sus dudas acerca del texto transmitido por los primeros editores de la pieza ${ }^{15}$, planteando que entre las líns. 2 y 3 la inscripción debería contener el resto de la titulatura habitual de Tiberio: pontificado máximo, potestad tribunicia, consulado y, quizá, la renovación del imperium (como se observa, por ejemplo, en CIL II 4651, encontrado junto al puente de Alconétar ${ }^{16}$.

Sin embargo, un posterior estudio de la pieza, aportando ya fotografía de la misma tras ser desenterrada de nuevo (como vimos, en la edición original de la pieza no se aportaba imagen alguna), permitió ver que, efectivamente, no existe ninguna línea de texto entre las líns. 2 y 3 y que la inscripción no recogía ni más títulos ni más cargos imperiales. Aun así, Gómez-Pantoja seguirá considerando este texto completamente anómalo,

13. En el texto ofrecido por Río-Miranda (en CRC 16) constan interpunciones en líns. 1 y 2 , si bien sobre la pieza (siempre a través de las fotografías aportadas) no se observa ninguna en la primera de ellas.

14. Río-Miranda, «Nuevas aportaciones»; Esteban Ortega (en CILCC III 920).

15. Gómez-Pantoja (en comentario a HEp 10, 2000, 108).

16. CIL II $4651=$ Roldán, Iter, 51, n. $^{\circ} 30=$ CPILC $680=$ MVP $90=$ CILCC I $208=H E p O L$ 1636 = EDCS 05600022: Ti(berius) Caesar/divi Augustif(ilius) /Augustus pontif(ex) max(imus) / trib(unicia) potest(ate) XXVII / - . - - . 
planteando, en tanto que la fotografía ahora publicada (Fig. 5a) no permite ver el comienzo de las líns. 1-2, la posibilidad de poder restituir la fórmula ImP. CAESAR / DIVI F. AVGVSTVIS] que, en su opinión, resultaría una alternativa más aceptable ${ }^{17}$. Aunque Gómez-Pantoja no lo indique explícitamente, de aceptar (como ciertamente hacemos) esta posibilidad de lectura, resulta evidente que nos hallamos no ante un miliario de Tiberio, sino ante uno de Augusto.
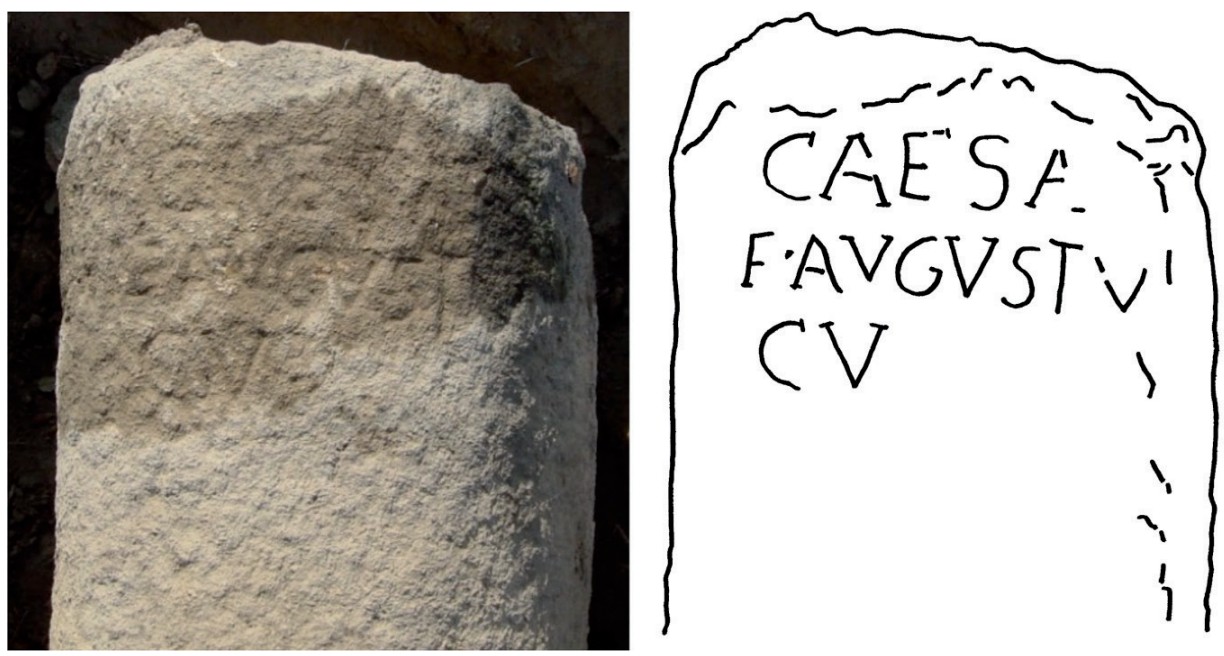

Fig. 5a-b: Vista frontal del miliario de Ahigal (fotografía de Río-Miranda e Iglesias, Ahigal, s.p.) y restitución de su texto (dibujo del autor).

De hecho, en una nueva edición de su artículo del año 2000, Río-Miranda e Iglesias aportarán una nueva fotografía de la pieza (Fig. $6 a)^{18}$ en la que enfocan a la parte izquierda del campo epigráfico, justo al inicio de las distintas líneas de texto que echara en falta en su momento Gómez-Pantoja. Sin embargo, en esta nueva fotografía tampoco se aprecian restos de estas pretendidas primeras letras de cada línea: es cierto que no se advierte la abreviatura Imp(erator) que aventurase Gómez-Pantoja, pero, de la misma forma, tampoco resultan visibles por lado alguno

17. Gómez-Pantoja (en comentario a HEp 14, 2005, 78).

18. Más que de una obra bibliográfica propiamente dicha, esta reedición se trata, en realidad, de un recopilatorio de las distintas inscripciones inéditas dadas a conocer en la revista Ahigal a lo largo de los volúmenes publicados durante los anteriores veinticinco años: https://www.academia.edu/10372805/25_aniversario_de_la_revista_AHIGAL. Agrupaci\%C3\%B3n_Amigos_de_Ahigal (consultado el 06/09/2020). 

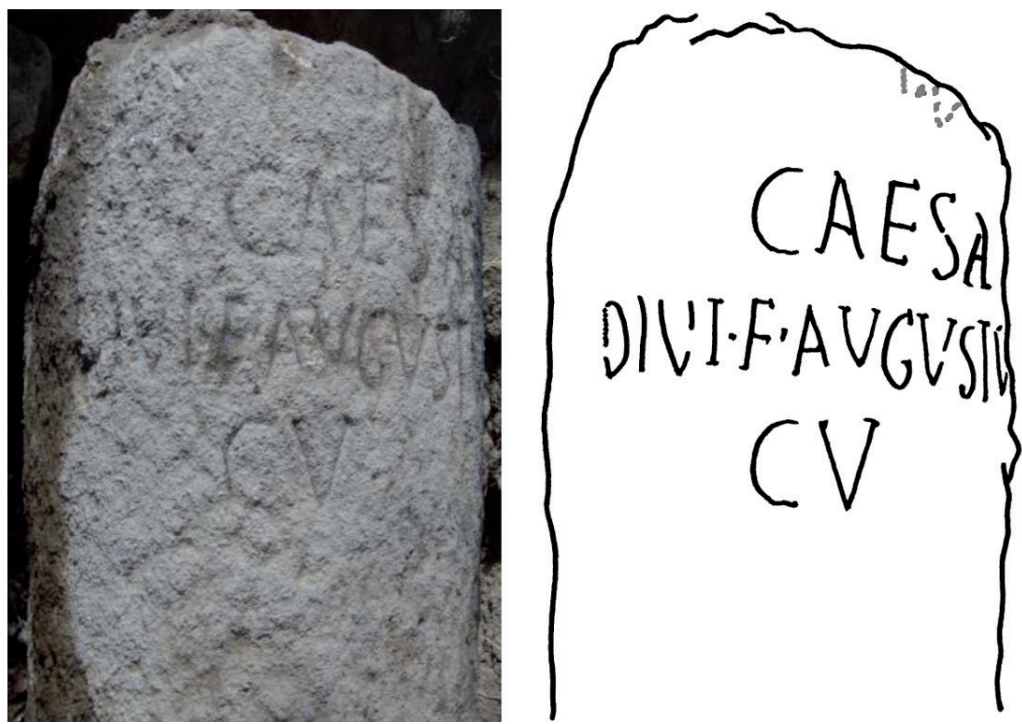

Fig. 6a-b: Vista lateral del miliario de Ahigal (fotografía de Río-Miranda e Iglesias tomada de https://www.academia.edu/10372805/25_aniversario_de_la_revista_AHIGAL_Agrupaci\%C3\%B3n_Amigos_de_Ahigal) y restitución de su texto (dibujo del autor).

ni la mención de $\operatorname{Ti}$ (berius) ni la interpunción que los editores originales restituyeran en esta misma línea antes de la palabra CAESAR.

Vistas estas cuestiones, y partiendo de la hipótesis de restitución textual ofrecida en su momento por Gómez-Pantoja (quien en su comentario en HEp 14 no conocía aún nuestra Fig. 6a), proponemos la siguiente nueva lectura de la inscripción:

\section{[Imp(erator)] Caesar / Divi $\cdot$ f(ilius) $\cdot$ Augustu[s] /CV}

Incluso aceptando la restitución del nombre TI(berius) al inicio del texto conservado, lo que resulta a todas luces evidente es que la filiación solo como DIVI $F$. no puede remitir sino a Augusto, ya que la filiación tiberiana es DIVI AVGVSTI F(ilius). Como ya hemos señalado, el término IMP(erator) no se aprecia - tampoco Ti(berius) — en ninguna de las distintas fotografías aportadas, ni al inicio de la primera línea del texto conservada ni en una presumible línea anterior. Al no contar con ninguna fotografía del fragmento desprendido del coronamiento de la pieza, no podemos desechar por completo la posibilidad de que este título constase en una primera línea de texto hoy perdida. De hecho, en la vista lateral de la pieza (Fig. 6) parecen percibirse trazos de uno o dos caracteres en la línea 
de fractura superior de la pieza (que señalamos en gris en nuestro dibujo 6b), si bien en la imagen frontal del campo epigráfico (Fig. 5) estos caracteres ya no resultan apreciables.

Consideramos que la existencia del término $\operatorname{Imp}($ erator) al inicio de esta titulatura imperial resulta a todas luces necesaria, pero creemos más probable su inclusión no en una hipotética primera línea de texto perdida, sino en el inicio hoy borrado de la primera línea de texto conservado, antes de la palabra CAESAR, pero sin que se aprecie tampoco la interpunción que sitúan aquí Río-Miranda e Iglesias (como sí que se aprecia la interpunción en la línea inmediatamente posterior). De esta forma, al situar los caracteres IMP en la misma línea que CAESAR, la inscripción reconstituida ofrece una ordinatio regular, con las tres líneas de texto bien encuadradas y centradas simétricamente a partir del eje marcado por el numeral miliario $C V$ de lín. 3.

\section{Acerca del miliario augusteo de Coria (Figs. 7-9)}

El análisis del miliario de Ahigal y nuestra consideración, frente a lo usualmente señalado en la bibliografía, de su carácter augusteo, nos lleva a aportar algunas notas acerca de otro miliario cacereño, localizado 37 $\mathrm{km}$ al suroeste de Ahigal, en este caso sí atribuido (al menos por parte de algunos investigadores) a Augusto.

Procedencia y localización: Se desconocen las circunstancias concretas del hallazgo de esta pieza, más allá de ser localizado en Coria ya en su edición original. Aunque ningún autor refiera nada sobre ello, lo cierto es que una serie de marcas paralelas que dañan el frente de la pieza y que podemos interpretar como posibles marcas de arado nos permiten plantear la posibilidad de que fuera hallado en un medio rural durante unas tareas agrícolas, si bien la falta absoluta de datos impide confirmar plenamente este planteamiento que aquí ofrecemos. Mantas señala que, en tanto que la pieza no aparece recogida en CPILC, habría aparecido entre 1977 (fecha de publicación de este primer corpus de epigrafía cacereña) y 1998 (cuando es publicado el $I L C)^{19}$, si bien las notorias carencias de la obra de Hurtado de San Antonio nos impiden saber si ya en 1977 la pieza se hallaba identificada en Coria. Lo cierto es que también se desconoce el lugar exacto de procedencia de esta pieza, señalando Mantas que bien pudiera provenir de la propia Coria, ya que inicialmente fue depositada

19. Mantas, "A política», 203. 
en el Ayuntamiento de la localidad ${ }^{20}$. No obstante, y dado que - como veremos- otros miliarios han conocido traslados de distancias considerables, no podemos dar por seguro el asiento original de la pieza en la misma Coria, ni siquiera en sus cercanías. Fuera como fuese, y más allá de que Curado señalase que la pieza perteneció en un primer momento a la colección epigráfica de Ciconia: Asociación para la Defensa de la Naturaleza y el Patrimonio Cultural ${ }^{21}$, lo cierto es que, cuando se publicó su editio princeps, este miliario se encontraba en el Ayuntamiento de Coria. En la actualidad se halla en el Museo de la Cárcel Real de la misma localidad, debiendo agradecer a Juan José Chaparro y a Ismael Asensio, responsables de la institución, las facilidades que nos dieron a la hora de acceder a la pieza, así como su amabilidad y entusiasmo a la hora de ayudarnos durante el análisis de la misma.

Soporte y estado de conservación: Nos hallamos ante el fragmento superior de un miliario de granito rojizo de grano fino. Su forma es bastante irregular: la sección de la pieza no es completamente cilíndrica (Fig. 7), pues la parte del campo epigráfico se halla notablemente alisada - como se observa también en los casos de los miliarios de Ahigal (Figs. 4-6) o de Moncarapacho (Fig. 3), aunque en este último se observa una forma tendente a lo prismático algo más acusada ${ }^{22}$ - pero tampoco de forma esteliforme como los hitos de Fuenteguinaldo (Fig. 1), Argomil o Alfaiates (Fig. 2). Por ello no podemos compartir la consideración de "miliario prismático" que le atribuyen Curado o Mantas ${ }^{23}$. El miliario se encuentra fracturado a partir de la lín. 4. Y, aunque el coronamiento se halla también bastante dañado, es sobre todo el lateral derecho de la

20. Mantas, "A política», 204.

21. Curado, "Notas", 66.

22. Compartimos con Salinas y Palao ("Nuevo miliario», 275) la idea de que este miliario de Moncarapacho, más que un hito prismático como los de Alfaiates o Fuenteguinaldo, se trata probablemente de un hito originalmente cilíndrico que, con posterioridad, fue parcialmente desbastado, adoptando una forma cuadrangular muy tosca. Las fotografías de estas piezas (Figs. 1-3) permiten observar las evidentes diferencias de formato entre el miliario de Moncarapacho (ciertamente alisado, pero cuyos bordes presentan una forma redondeada que remitiría a su constitución cilíndrica original, presentando además en su parte inferior lo que parecen ser los restos de su base cuadrangular, típica de los miliarios columniformes altoimperiales) y los hitos de Fuenteguinaldo y Alfaiates (auténticas inscripciones esteliformes, de grosor notablemente inferior y de superficie completamente recta en todas sus caras -también en sus bordes laterales-). No cabe duda de que el miliario cauriense (Fig. 7) presenta mayores semejanzas con el hito de Moncarapacho que con los Alfaiates o Fuenteguinaldo, aspecto sobre el que profundizaremos más adelante.

23. Mantas, As vias, 251, fig. 86; "Da capital», 262; Curado, "Notas», 66. 

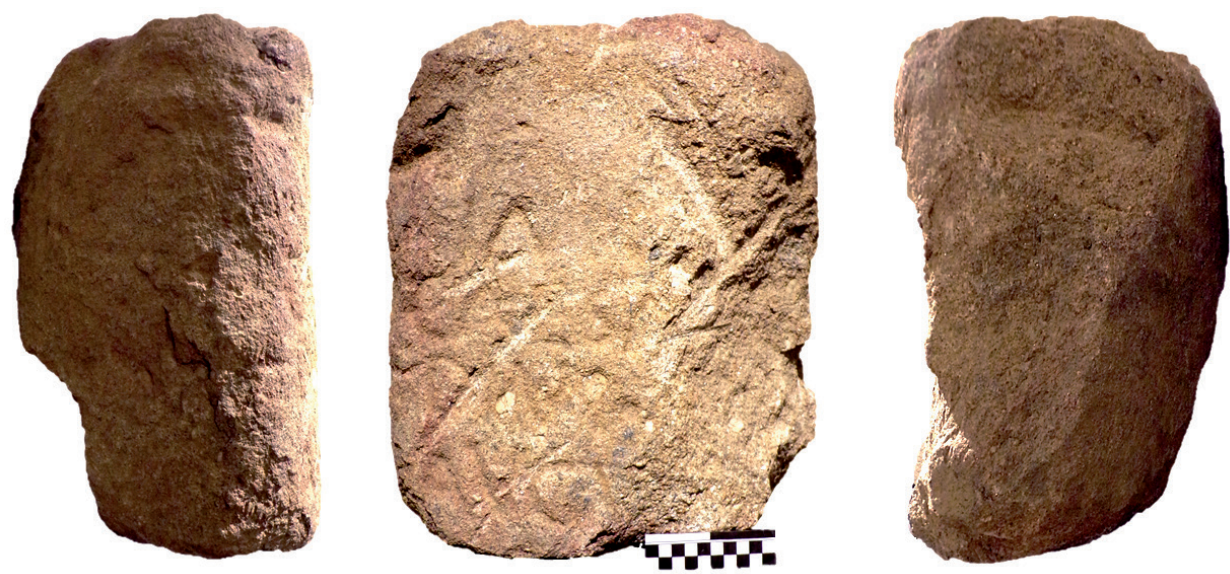

Fig. 7: Vistas laterales y frontal del miliario de Coria en el Museo de la Cárcel Real (fotografías del autor).

pieza el que más deteriorado se encuentra, habiéndose perdido los últimos caracteres de cada una de las cuatro líneas del texto conservado.

Medidas: Sus editores originales le otorgaron unas medidas de (43) $\mathrm{cm}$ de altura x $40 \mathrm{~cm}$ de ancho x $24 \mathrm{~cm}$ de grosor $^{24}$. Esteban Ortega, en cambio, le da $(40) \mathrm{cm}$ de altura x $27 \mathrm{~cm}$ de diámetro ${ }^{25}$. Por nuestra parte, medimos una altura máxima de (44) $\mathrm{cm}$ y, dada la imposibilidad de ofrecer un diámetro de la pieza (en tanto que su sección no es completamente cilíndrica), le damos unos $39 \mathrm{~cm}$ de anchura y un grosor máximo de $25 \mathrm{~cm}$.

Notas paleográficas: Nos encontramos ante capitales cuadradas muy rústicas, unas características paleográficas que, en opinión de Mantas, remiten a una datación muy temprana ${ }^{26}$. Como en el caso del miliario de Ahigal, también en este se aprecian los ápices de las letras VO I, pudiendo destacarse, asimismo, la singular forma de la $D$ de lín. 3. Altura de las letras: $5 \mathrm{~cm}$. Interpunción circular al final del texto conservado en lín. 3.

Referencias: ILC 90 (reseñado por Mantas, "Recenção", 285) = HEp 8, 1998, 57 (con comentario de Gómez-Pantoja) = Curado, "Notas", 66-67 = CILCc IV 1254 = Mantas, "A política", 203-204, n. ${ }^{\circ} 2=$ HEpOL $22677=$ EDCS 19100724 .

24. Sánchez Albalá y Vinagre Nevado (en ILC 90).

25. Esteban Ortega (en CILCC IV 1254).

26. Mantas, "A política», 204. 

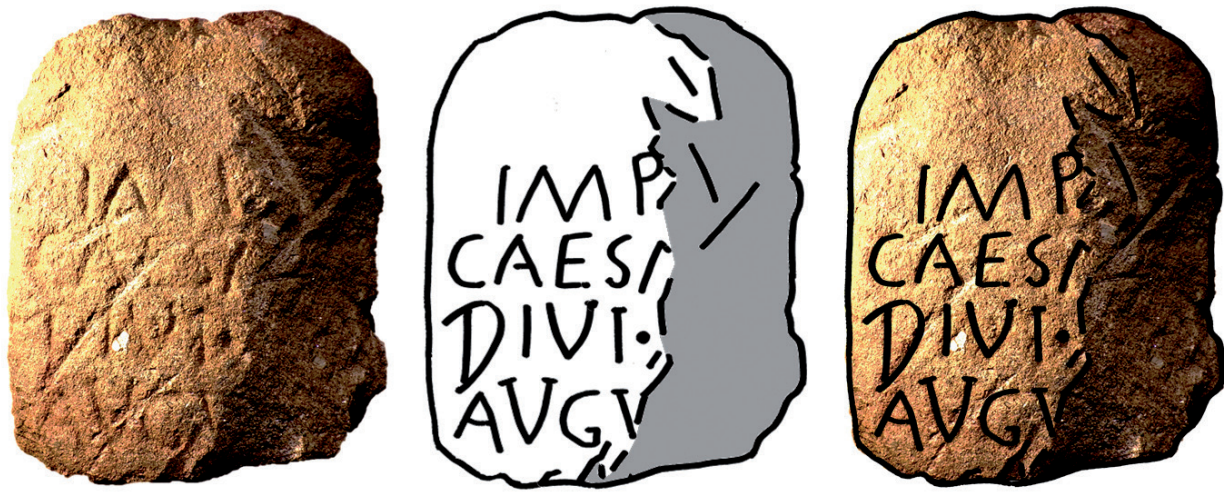

Fig. 8: Vista frontal del miliario de Coria y restitución del texto conservado (fotografía y dibujos del autor).

\section{Texto y comentario:}

Lectura de ILC (recogida en HEp 8): Imp(erator) / Caesa(r) / Divi / $\operatorname{Augu}($ sto) $[$ sic. $] /[--$ - .

Esteban Ortega adopta esta misma restitución, si bien la corrige, sustituyendo el dativo $A v G v(s t o)$ por el genitivo $A v G v(s t i)$ y señalando la interpunción en lín. 3 tras $D I V{ }^{27}$. Por su parte, Mantas apunta que cree "poder vislumbrar uma primeira linha, que conteria a indicação miliária, um valor próximo das 90 milhas ${ }^{28}$. De aceptar esta idea (que ciertamente no podemos compartir, en tanto que personalmente no observamos resto de carácter alguno en esta parte inicial de la pieza, como tampoco lo apreciara $\operatorname{Curado}^{29}$ ), veríamos que esta pieza seguiría el modelo de los hitos augusteos de Fuenteguinaldo y Alfaiates, en los que el numeral relativo a las millas aparece en el coronamiento de la pieza, antes de la titulatura imperial, y no tras esta, como sucede en la mayor parte de las inscripciones de carácter miliario.

A pesar del mal estado en que se encontraba el fragmento, que corresponde solo a la cabecera de la pieza, ya sus primeros editores consideraron

27. Esteban Ortega (en CILCC IV 1254).

28. Mantas, "A política", 203.

29. Curado, "Notas", 67: "Não há qualquer vestígio de gravação de um numeral no início do texto, que, a ter existido, seria sempre inferior a XCm. De hecho, es de destacar que esta parte superior de la pieza, anterior a la lín. 1 del texto, es precisamente la que mantiene su superficie en mejor estado de conservación, por lo que la existencia de cualquier carácter, de haberlo, sería perfectamente perceptible. 
que se trataba de un miliario de Augusto ${ }^{30}$. Por su parte, para Gómez-Pantoja resulta dudoso que fuese realmente un miliario de época augustea ${ }^{31}$, dudas que, más recientemente, comparte Esteban Ortega ${ }^{32}$. Frente a estas consideraciones, Curado o Mantas dan por seguro que nos hallamos ante un miliario de Augusto ${ }^{33}$, opinión con la que estamos plenamente de acuerdo. En función de su carácter augusteo, la lectura que ofrecemos es la siguiente:

Imp(erator) / Caesạ [r] / Divi · [f(ilius)]/Augu(stus) / - -

Aun sin poder descartar por completo la posibilidad de que el título Augustus apareciera por extenso, pero dividido en dos líneas, creemos que el texto paralelo de Ahigal nos permite considerar como más probable que a este miliario de Coria únicamente le faltaría la última línea del texto, referente, sin duda, al numeral que marcaría la milla. No llegamos a percibir, como ya avanzamos, ningún resto de letras en la pretendida línea inicial que vislumbrara Mantas ${ }^{34}$ : quizá podamos plantear que estos supuestos caracteres aludidos por Mantas no son sino trazos fruto del deterioro de la pieza por este extremo superior, pero, en todo caso, lo cierto es que no se observa ningún carácter antes de la primera línea del texto. Sin embargo, bajo las letras $V G$ de lín. 4 Curado dice apreciar un arco de círculo al nivel de la rotura inferior de la pieza, que interpreta como "correspondente à parte superior de um $O$, da abreviatura $\cos$ na $5^{\text {a linha». }}$ En función de esto, Curado ofrece la siguiente propuesta de reconstrucción del epígrafe:

Imp(erator) / Caesa $[r] /$ divi $\cdot[f(i-$ lius)] / Augu[stus / co(n)s(ul) XI / imp(erator) VIII $\beta^{55}$

30. Sánchez Albalá y Vinagre Nevado

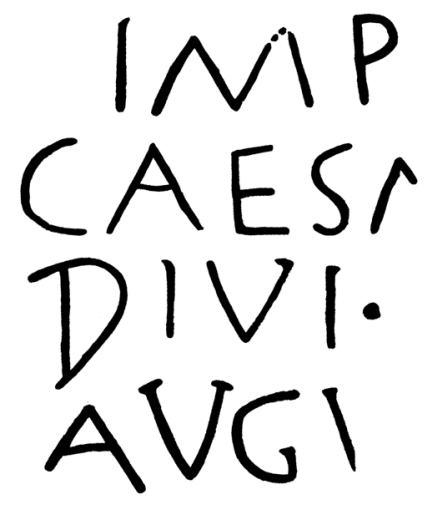

actongang

Fig. 9: Calco del texto del miliario de Coria tomada por el autor directamente sobre la pieza en el Museo de la Cárcel Real. (en $I L C$ 90).

31. Gómez-Pantoja (en comentario a HEp 8, 1998, 57).

32. Esteban Ortega (en CILCC IV 1254).

33. Mantas, «Recenção», 285; «A política», 203-4, n 2; Curado, "Notas», 66-67.

34. Mantas, "A política», 203.

35. Curado, «Notas», 66-67. Esta restitución textual es la que aparece recogida igualmente en la cartela que acompaña al miliario en el Museo de la Cárcel Real de Coria. 
Como veremos, esta restitución del consulado XI y de la VIII aclamación imperial de Augusto se basa exclusivamente en la relación textual y cronológica que Curado establece entre esta pieza y los hitos augusteos de Fuenteguinaldo o Alfaiates. Por nuestra parte, sin embargo, no llegamos a observar ningún posible resto de letra en lín. 5. Y además, en caso de que así fuera, los paralelos de Casar de Cáceres o de Ahigal, como veremos, nos llevarían a plantear que en la línea final del texto debió registrarse no una hipotética mención consular, sino, en realidad, el numeral miliario de la pieza (que perfectamente pudo contener una $C$, cuyo arco superior bien pudo ser confundido por Curado con el coronamiento de una o). Pero, insistimos, nuestro análisis del miliario nos lleva a descartar la presencia de restos de esta presumible lín. 5 de texto.

Por otro lado, vemos que en su restitución del texto Mantas desarrolla por completo en lín. 2 la palabra $C_{A E S A R}{ }^{36}$, si bien la $-R$ final se halla, como claramente se aprecia en la fotografía, perdida. Tampoco creemos que se tratase de una abreviatura CAESA(r), opinión mantenida por los primeros editores o por Esteban Ortega ${ }^{37}$, pues la existencia de esta $-R$ final, hoy perdida, se ajusta mucho mejor a una ordinatio regular y centrada, como recoge la restitución de Curado y como se observa también en el caso ya visto del miliario de Ahigal.

La abreviatura que planteamos del término AvGV(stus) en lín. 4, aunque presentada meramente como la hipótesis que creemos más probable, se ajustaría también a una ordinatio centrada, ya que, por extenso, el término AvGV[STVS] (restituido, por ejemplo, por Curado) sobrepasaría con creces hacia la izquierda el campo epigráfico marcado por las dos líneas precedentes (en las que solo faltaría una letra, hoy borrada, en cada renglón, y no cuatro). Aunque a priori esta abreviatura $A v G v(s t u s)$ que planteamos para este miliario de Coria pueda resultar cuando menos extraña, lo cierto es que sin salir siquiera de territorio lusitano la encontramos también, por ejemplo, en el miliario domicianeo de la vecina localidad de Cañavera ${ }^{38}$, así como también, ya en territorio de la Citerior, en el miliario — también de Augusto- de Cúllar (Granada) ${ }^{39}$. Otra posibilidad a considerar, también acorde con la ordinatio regular y centrada que planteamos

36. Mantas, "A política», 203.

37. Sánchez Albalá y Vinagre Nevado (en ILC 90); Esteban Ortega (en CILCc IV 1254).

38. Castro y Valiente, "Un nuevo miliario" = HEp 2013, $102=$ HEPOL $32547=$ EDCS 74300386: Imp(erator) C[aes(ar)] [D]ivi / Vespa[siani] f(ilius) / Domi[tianu]s / Augu(stus) [Germa]nic[us] / pont[if(ex)] [max(imus) t]rib(unicia) / potes[t(ate) - - - p(ater) p(atriae) i]mp(erator) / XIIII c[ensor p]er/petu(us) c[o(n)s(ul) X?]III vi/[as et pontes - - -].

39. CIL XVII/1, $84=A E$ 1977, $450+1982,627=$ HEPOL $5991=$ EDCS 09301028: Imp(erator) Caes(ar) divi f(ilius) / Augu(stus) co(n)s(ul) XI / trib(unicia) pot(estate) XVI imp(erator)/XIII pon(tifex) max(imus). 
para este miliario, sería la restitución del título imperial como $A v G v[s(t u s)]$. Nos hallaríamos, es cierto, ante una forma también bastante anómala, si bien volvemos a encontrarla en no pocos miliarios hispanos como, por ejemplo, en el hito hadrianeo CIL II 4678 de la localidad salmantina de Peromingo ${ }^{40}$, así como en el miliario augusteo de Castiliscar (Zaragoza) ${ }^{41}$.

En suma, ya se desarrolle el título imperial como Avgv(stus), Avgr[stus] o $A v G V[s(t u s)]$, y siempre sin poder descartar por completo la posibilidad de un título Augustus desarrollado por extenso pero quizá dividido en dos líneas, a juzgar por el texto conservado y por las distintas restituciones planteadas de los caracteres perdidos o abreviados, la atribución de este miliario cauriense a Augusto parece clara. Y es que, como bien apunta Mantas, resulta a todas luces evidente la existencia de una interpunción en lín. 3 tras la palabra $D I V T^{42}$. Aunque no se trataría, ciertamente, de un caso único, creemos al igual que este autor que esta interpunción invita a restituir una palabra justo después en esta misma línea, palabra que no puede ser sino F(ilius): una vez más la ordinatio parece exigir que esta última palabra de la lín. 3 solo sea abreviada con una letra, manteniéndose así la simetría y la centralidad del texto.

Además, y más allá de que la fórmula DIVI F. AvGVSTVS solo puede referirse al primer emperador romano, ninguna otra titulatura imperial se adapta al texto conservado en esta pieza. Así, al igual que en el miliario de Ahigal, resulta imposible restituir aquí, por ejemplo, la titulatura de Ti(berius) CAESAR DIVI AVG(usti) F(ilius) AvgVSTVS, en tanto que sabemos que Tiberio rechazó el praenomen Imperator que se constata aquí en lín. 1 y que solo en muy contadas ocasiones aparece en las inscripciones de este emperador. Pero, incluso aceptando que el título ImP(erator) de este miliario pudiera referirse a Tiberio, la titulatura resultante (un tan hipotético como anómalo IMP. TI. CAESAR AVGVSTVS DIVI AVGVSTI F.) resulta nuevamente imposible de ajustar: aun pudiendo aceptar una lín. 1 como IMP(erator) [Ti(berius)], la lín. 2 resultaría demasiado larga al incluir los títulos CAESA[R AVGVSTVS] -incluso abreviando este segundo como AVG(ustus), lo que chocaría con el desarrollo previo, por extenso, de CAESAR-, para a continuación dejar en lín. 3 solo los cuatro caracteres de DIVI · (con

40. CIL II $4678=$ Roldán, Iter, 61, n. ${ }^{\circ} 84=$ MVP $156=$ ERPSa $217=$ HEpOL $22854=$ EDCS 05600049: [I]mp(erator) Caes(ar) divi /Traiani · Part<h>icif(ilius) / divi Nervae nepos / Traia(nus) <H>adria(nus) Augus(tus) / ponti(fex) max(imus) trib(unicia) potes(tate) / V co(n)s(ul) III refecit / CXL.

41. CIL XVII/1, $170=A E$ 1984, $585=$ HEPOL $19137=$ EDCS 08400355: Imp(erator) [C]aesar divi [f(ilius)] / Augu[s(tus)] co(n)s(ul) XII / trib[u]nic(ia) potes(tate) XV[IIII] / imp(erator) [XI]III pontifex / ma $<x>s u$ (mus) l(egio) VI / m(ilia) XX.

42. Mantas, "A política", 203. 
el problema añadido y ya referido de esta interpunción al final de línea), constando finalmente en lín. 4, bien abreviado o bien por extenso, el final de esta pretendida filiación AvGV(Sti) [F(ilius)].

Al igual que ocurre con el miliario de Ahigal, y frente a la propuesta de restitución de Curado (seguido parcialmente a este respecto por Mantas) según la cual la pieza mostraría una paginación y texto idénticos - $\mathrm{O}$ cuando menos semejante- a los constatados en los hitos de Alfaiates, Argomil o Fuenteguinaldo ${ }^{43}$, lo cierto es que la lacónica titulatura imperial que ofrece este miliario impide otorgarle una fecha precisa más allá del arco temporal del principado augusteo, esto es, entre el 27 a. C. y el $14 \mathrm{~d}$. C. No obstante, y siempre de seguir la interpretación de Curado y Mantas (que, insistimos, por nuestra parte no podemos compartir), podría precisarse una datación paralela a la de los ejemplares con los que relacionan este miliario:

Permite desde logo inseri-los no mesmo grupo e relacioná-los todos com a mesma estrada, cuya construção do tramo lusitano remonta ao período entre 25 a.C. e 23 a.C., de acordo com a titulatura presente nos miliarios que se conservaram ${ }^{44}$.

Pero creemos que esta datación únicamente se sustenta en la hipotética vinculación del miliario cauriense a la misma ruta (o, más bien, conjunto de rutas) que los miliarios de Alfaiates o Fuenteguinaldo, y no con respecto al iter ab Emerita Asturicam, de donde sí procede sin duda el miliario de Ahigal analizado supra ${ }^{45}$, así como también el de Casar de Cáceres. Y es que, como veremos a continuación, no podemos descartar por completo que la pieza de Coria pudiera tener su origen en esta misma Vía de la Plata.

\section{Cuestiones viarias en torno al miliario augusteo de Coria}

No cabe duda alguna de que la nueva lectura augustea del hito de Ahigal permite hablar de un nuevo miliario de Augusto en el tramo lusitano de la Vía de la Plata, un nuevo miliario que sumar al ya conocido de Casar de Cáceres. Más problemas de atribución viaria presenta, en cambio, el hito de Coria. Sus editores originales, seguidos a este respecto por

43. Curado, "Notas", 66-67; Mantas, "A política», 204.

44. Mantas, "A política", 204.

45. Frente al desconocimiento sobre el origen y circunstancias concretas del hallazgo del hito cauriense, el hecho de que el miliario de Ahigal se encontrase enterrado junto a la antigua calzada, justo en el punto marcado precisamente por la milla CV indicada en su texto, permite considerar que no sufrió traslado alguno y que se hallaba in situ, en su asiento original. 
Esteban Ortega, lo consideraron como el primer miliario testimoniado de la así denominada Vía Dalmacia, la antigua calzada romana y ramal de la Vía de la Plata que, desde la mansio de Turmulos (en el vado del Tajo a la altura de Alconétar), pasaría por Caurium para superar luego la Sierra de Gata en dirección a Ciudad Rodrigo (tradicionalmente identificada con Mirobriga ${ }^{46}$. En cambio, Mantas defenderá que la vía a la que correspondía originalmente este miliario seguiría no tanto hacia el área salmantina, sino más bien, ya por la ciuitas Igaeditanorum, ya por la región de Sabugal, hasta la Serra da Estrela, formando así parte del conjunto de itinerarios centrados en la conexión entre Augusta Emerita y el Noroeste peninsular. No obstante, el autor reconoce la existencia de un segundo ramal procedente de Salmantica y Mirobriga, que sería el señalizado por el hito igualmente augusteo de Fuenteguinaldo:

A sua atribução à estrada que as fontes medievais denominan Via Dalmacia, proposta por Sánchez e Vinagre, será aceitável apenas se o miliário pertenecer ao troço entre Turmulos, obscura estação na via Emerita-Asturica, e Caurium, uma vez que os restantes testemunhos miliários que indicamos [Fuenteguinaldo, Alfaiates y Argomil, aunque de este último Mantas niegue su carácter auténticamente miliario] sugerem uma directriz alheia a Mirobriga (Ciudad Rodrigo), o que não impede, naturalmente, que tenha existido uma estrada procurando esta última cidade ${ }^{47}$.

Por nuestra parte, creemos que no se puede descartar por completo que este miliario cauriense procediese en realidad de la Vía de la Plata, distante apenas unos $20 \mathrm{~km}$ de Coria. Como ya hemos indicado, Mantas señala la existencia de una primera línea de texto en la pieza que indicaría un numeral cercano a las 90 millas $^{48}$, número que correspondería a la distancia desde Augusta Emerita hasta la propia Coria. La mansio de Turmulos, en la milla LXVI del iter ab Emerita Asturicam, marcaría el punto en que la ruta se desdoblaría: hacia el noreste seguiría su trazado con dirección Capera, Salmantica y Asturica Augusta, mientras que en dirección noroeste enlazaría con la antigua Caurium, siendo en este ramal en el que habría estado originalmente este miliario, a unas veinticuatro millas de Turmulos (las necesarias entre la milla LXVI de la mansio de Turmulos y la milla \pm XC que considera Mantas en el texto de esta pieza).

46. Sánchez Albalá y Vinagre Nevado (en ILC 90); Esteban Ortega (en CILCc IV 1254).

47. Mantas, "A política», 204. La misma idea ya planteada en Mantas, «Recensão», 208; As vias, 251, o, más recientemente, en Mantas, "Da capital», 262-264.

48. Mantas, "A política», 203. 
Pero, por otro lado, justo en la horizontal de Coria, a $21 \mathrm{~km}$ hacia el este, la Vía de la Plata pasa por la localidad de Galisteo, donde, a propósito de CIL II 4653-4654, Puerta considera que se emplazarían las millas LXXXVIII-XCV de la calzada ${ }^{49}$. Por tanto, un numeral cercano a las XC millas resulta perfectamente compatible con la posible ubicación original del miliario en la Vía de la Plata ${ }^{50}$. La distancia entre Coria y la zona de Galisteo no resulta excesiva para poder plantear un posible traslado de la pieza, sobre todo teniendo en cuenta el reducido tamaño del fragmento conservado. De hecho, sin salir siquiera de este mismo iter ab Emerita Asturicam, y hablando ya de piezas conservadas completas y de gran formato, vemos, por ejemplo, cómo el miliario correspondiente a CPILC $745=$ MVP 97 = CILCC III 995 fue trasladado cerca de $19 \mathrm{~km}$ desde su asiento original en la vía, también en la zona de Galisteo, hasta su ubicación actual en la localidad de Malpartida de Plasencia ${ }^{51}$. Lo mismo sucede con otro miliario (MVP $177=$ ERPSa 204) localizado en la finca El Carnero (en el municipio salmantino de Calzada de Don Diego), pero cuya milla $C L X V$ indica que procedería del tramo de la calzada coincidente hoy con la dehesa de Calzadilla de Mendigos (término municipal de Membribe de la Sierra), más de $20 \mathrm{~km}$ hacia el este de su lugar de aparición. Semejante distancia fue la recorrida también por los tres miliarios $(M V P$ 178-180 = ERPSa 222-226) procedentes igualmente de esta finca de Calzadilla de Mendigos, hasta su posterior ubicación en la finca El Linejo, ya en el término de Matilla de los Caños del Río, a $23 \mathrm{~km}$ al oeste de su ubicación original. Y una distancia aún mayor, de unos $47 \mathrm{~km}$, es la que separa Fuenterroble de Salvatierra (de donde procedería el miliario CIL II $4682=$ $M V P$ 169) de la localización posterior de esta pieza, en el antiguo palacio de los condes de Fuentes, en la ciudad de Salamanca.

Sin embargo, lo cierto es que para el caso concreto del miliario de Coria nada podemos asegurar a este respecto, en tanto que creemos que ni resulta demostrable que efectivamente marcase una milla cercana a la $\mathrm{XC}$ ni, sobre todo, que su asiento original se encontrase en la propia Coria o en su entorno inmediato. Aun así, Curado o Mantas han subrayado las semejanzas en texto y paginación entre el miliario cauriense y los hitos de Fuenteguinaldo o Alfaiates, así como también con respecto al epígrafe

49. MVP 95.

50. Sin embargo, como ya señalamos, en las fotografías aportadas no logramos apreciar el numeral que sí vislumbrase Mantas.

51. Puerta (en MVP 97) y Esteban Ortega (en CILCC III 995) no cuestionan que este miliario procediese efectivamente de la Vía de la Plata. Sin embargo, recientemente este último autor (en $F E$ 130: 547) ha planteado que pudiera pertenecer en realidad a un ramal secundario de esta calzada que conectaría Capera con Augustobriga. 
augusteo de Rabanales (Zamora), ya en la Citerior, que el segundo de estos autores tendrá igualmente por un miliario relacionado con el sistema viario augusteo señalizado por los hitos de Fuenteguinaldo o Alfaiates ${ }^{52}$.

Ciertamente, los miliarios de Fuenteguinaldo, Alfaiates o Argomil - consideremos o no que este último se trata realmente de un auténtico miliario- parecen centrar la obra viaria augustea muy especialmente en este sector de la antigua Lusitania limítrofe entre la provincia salmantina y el distrito portugués de Guarda. Sin embargo, la existencia del miliario de Augusto de Casar de Cáceres, al que hemos de sumar ahora también el procedente de Ahigal, permite redimensionar la presencia de Augusto en la Vía de la Plata, y más aún si consideramos que, efectivamente, también el de Coria estaba ligado a esta vía: aunque las distancias en línea recta entre Coria y Casar de Cáceres (49 km) o Ahigal $(37 \mathrm{~km})$ no se diferencian mucho de las que la separan de Fuenteguinaldo y Alfaiates (49 y $53 \mathrm{~km}$ respectivamente, sin olvidar que, en estos casos, además, se franquean las sierras de Gata y da Estrela), la propia situación geográfica en la red viaria romana parece primar la vinculación del miliario cauriense con la Vía de la Plata de forma mucho más evidente que con el eje Fuenteguinaldo-Alfaiates (Fig. 10).

\section{A MODO DE CONCLUSIÓN}

Ya nos hemos referido a las similitudes que Curado o Mantas han planteado, en cuanto a texto, paginación o formato, entre el miliario de Coria y los hitos de Alfaiates o Fuenteguinaldo. Pero lo cierto es que, por nuestra parte, podemos señalar que en lo relativo a las características físicas del soporte (aun reconociendo que actualmente la pieza no sea completamente cilíndrica, estamos lejos de poder considerarla como un miliario prismático) o a su formulario (ubicación original del número de milla tras la titulatura imperial, así como ausencia de las menciones consulares, de la tribunicia

52. Mantas "A política», 201 y 204. La inscripción de Rabanales (HEp 11, 2001, $588=$ AE 2003, $961=$ HEPOL 24607 = EDCS 28800708) muestra un texto prácticamente idéntico al de los miliarios augusteos lusitanos, aun sin poder precisar si en la parte perdida de la inscripción se mencionaría el consulado y las aclamaciones imperiales (como en los hitos de Fuenteguinaldo, Alfaiates o Argomil) o si solo constaría la onomástica imperial básica (como en los de Casar de Cáceres, Ahigal o Coria): Imp(erator) / Caesar [Divi] / f(ilius) Aug(ustus) / - . - . - Seguimos aquí el desarrollo en nominativo del texto que plantea Mantas ("A política", 201), con quien compartimos también la interpretación de esta pieza como miliario, frente al carácter honorífico que le dieron Rodríguez Colmenero y Ferrer Sierra, «Por tierras», 237-238. 


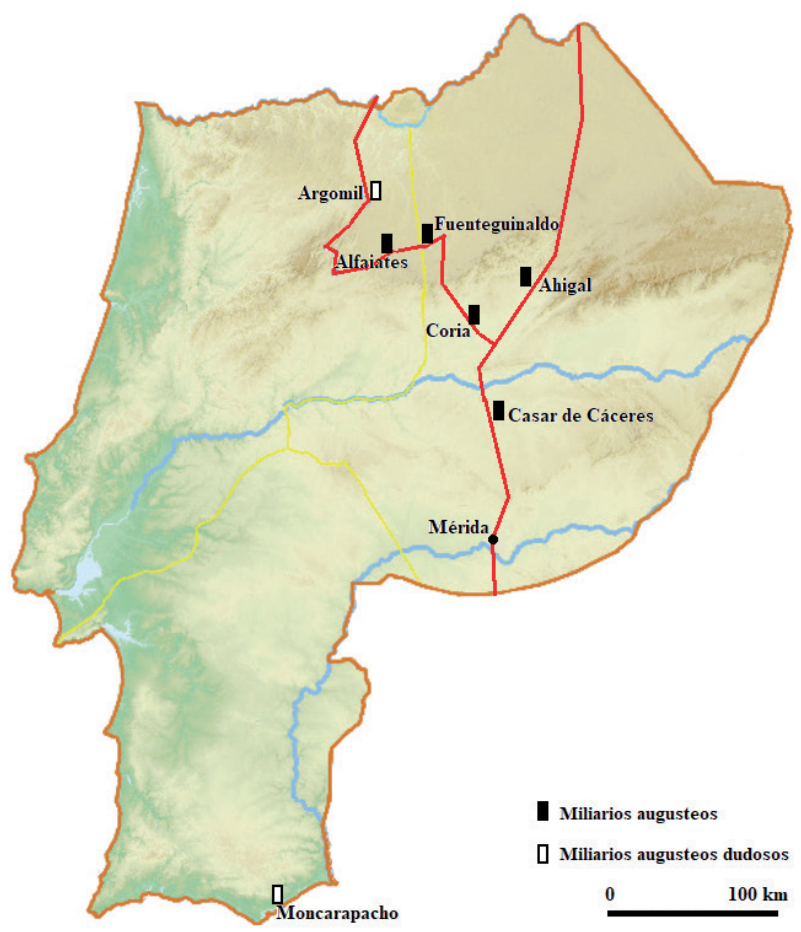

Fig. 10: Miliarios augusteos en Lusitania (elaboración propia, basada en los itinerarios planteados por Mantas, "Da capital», 202, fig. 4).

potestas y de las aclamaciones imperiales) este miliario cauriense se ha de vincular no tanto con los del eje Fuenteguinaldo-Alfaiates-Argomil, sino más bien con los del iter ab Emerita Asturicam, es decir, con los de Casar de Cáceres $^{53}$ y Ahigal. Y aquí radica verdaderamente la importancia de la consideración como miliario realmente de Augusto (y ya no de Tiberio)

53. Aunque, como reconoce, por ejemplo, Mantas ("A política", 203), no contamos con ninguna información sobre las características del soporte, el hecho de que, desde el primer momento, ya desde su noticia original, esta pieza de Casar de Cáceres fuese identificada indudablemente como un miliario nos lleva a considerar como muy probable que presentase una forma más o menos cilíndrica, como resulta en la gran mayoría de inscripciones miliarias. De hecho, el propio Mantas ("A política", 207) considera que este miliario "pertence a um grupo com características distintas" a los de Fuenteguinaldo o Alfaiates. Y es que no hemos de olvidar que el que se haya debatido largo y tendido acerca del carácter miliario o no de las inscripciones de Alfaiates y Argomil (vid. supra n. 5 y n. 6) se debe, precisamente, a que no presentan la típica forma cilíndrica de los hitos miliarios. 
del hito de Ahigal, a la hora de poder interpretar y contextualizar de forma correcta el paralelo de Coria. Sirva la siguiente tabla (Fig. 11) para comprobar que, efectivamente, en cuando a su estructura textual, el miliario de Coria se asemeja más al conjunto de los otros hitos augusteos conocidos en la Vía de la Plata, y no tanto con aquellos otros más noroccidentales del eje Salamanca-Guarda, representando, también frente al resto de miliarios augusteos hispanos, un conjunto muy bien definido precisamente por la omisión de todo cargo más allá de la onomástica imperial básica ${ }^{54}$.

Aunque, como señalase Mantas, el número de miliarios augusteos en Lusitania sea muy reducido ${ }^{55}$, la atribución a Augusto de los hitos de Ahigal y de Coria (novedosa en el caso del primero, confirmada definitivamente - a nuestro juicio - en el caso del segundo) permite sumar estas dos piezas a este limitado catálogo conformado previamente por los hitos de Casar de Cáceres, Fuenteguinaldo, Alfaiates y, con más dudas, Argomil y Moncarapacho. Y, además, las evidentes similitudes en cuanto a texto, ordinatio y formato, entre los miliarios de Ahigal y de Coria nos llevan a considerar, cuando menos en calidad de hipótesis a tener en cuenta desde ahora, la vinculación del miliario cauriense con la Vía de la Plata, una

54. Todos los demás miliarios augusteos conocidos en las provincias hispanas presentan una titulatura imperial más completa, constando los consulados, las aclamaciones imperiales, el número de la tribunicia potestas desempeñada o el cargo de pontifex maximus. Salvando el caso de la inscripción de Rabanales (en donde, como ya dijimos, no podemos precisar si en la parte perdida del texto se mencionarían estos cargos imperiales o si, por el contrario, solo constaría la onomástica imperial mínima), únicamente un miliario hispano se escapa a esta tendencia general. Nos referimos a HEPOL 7789 = EDCS 14700349 de la región de Aquae Flaviae, en la Citerior, en donde Augusto aparece solo como Imp(erator) Caes(ar) / August [us], discutiéndose si en la parte perdida de la inscripción, al final de lín. 1, aparecería o no la filiación Divif., pero sin ningún título más. En el conjunto del Imperio, encontramos esta misma tónica (representación de la onomástica imperial junto con todos los títulos y cargos desempeñados) en los miliarios augusteos, aun pudiendo mencionar como posible paralelo el hito AE 1932, 5 = EDCS 16100339 de Larissa, en Macedonia, donde al igual que en los miliarios augusteos del iter ab Emerita Asturicam solo consta la nomenclatura imperial básica y el numeral de la milla correspondiente: Imp(erator) Caesar / divif(ilius) / Aug[u]stus / CXIII.

55. Mantas, "A política», 199. Compartimos plenamente, además, la matización realizada por este mismo autor ("A política", 195) en el sentido de que resulta evidente que trabajamos con una muestra muy reducida del número de miliarios augusteos que posiblemente existieran, lo cual obliga a tratar siempre con cautela las generalizaciones o conclusiones que de este tipo de estudios pudieran extraerse. Aun así, y en tanto que el principado augusteo (continuado luego directamente por sus sucesores Julio-Claudios) constituyó el periodo clave en el diseño y estructuración de la red viaria hispana (y, para lo que a nuestro trabajo respecta, lusitana), no deja de sorprender la escasa presencia de miliarios de este momento concreto. 


\begin{tabular}{|c|c|c|c|c|c|}
\hline$\frac{\text { Coria }}{\text { IMP }}$ & $\frac{\text { Ahigal }}{\text { IIMPlCAFSAR }}$ & $\frac{\text { Casar de Cáceres }}{\text { IMP CAFSAR }}$ & $\frac{\text { Fuenteguinaldo }}{\text { CXX }}$ & $\underline{\text { Alfaiates }}$ & $\frac{\text { Argomil }}{\text { IMP }}$ \\
\hline IMP & & IMP CAESAR & CXX & CX[-- - ] & \\
\hline CAESA $[R]$ & DIVI F AVGVSTV[S] & AVGVSTVS & IMP & $\mathrm{IM}[\mathrm{P}]$ & CAESAR \\
\hline DIVI [F] & $\mathrm{CV}$ & LIX & CAESAR & CAESA $[R]$ & DIVI F \\
\hline AVGV & & & DIVI F & DIVI F & AVGVSTV[S] \\
\hline - - & & & AVGVSTVS & AVGVSTVS & $\cos \mathrm{XI}$ \\
\hline & & & $\cos \mathrm{XI}$ & $\operatorname{COS} \mathrm{XI}$ & IMP VIII \\
\hline & & & IMP X & IMP V[III?] & \\
\hline
\end{tabular}

Fig. 11: Comparativa estructural del texto del miliario de Coria con otros hitos augusteos. Tomamos únicamente piezas conocidas físicamente y no transmitidas solo por tradición manuscrita —ya que, como ha señalado recientemente Mantas ("A política», 210) al respecto del hito CIL II 4686 de Encinasola, la tradición manuscrita no siempre refleja fidedignamente la estructura textual original-; y en un estado de conservación suficientemente bueno como para conocer su distribución textual y el conjunto de la inscripción original.

vinculación que hasta la fecha no ha sido planteada por ninguno de los autores que, de una forma u otra, han tratado sobre esta pieza ${ }^{56}$.

De este modo, de un solo miliario augusteo —el de Casar de Cáceresen la que ciertamente fue la vía romana que más atención imperial recibió en toda la Lusitania $^{57}$, pasaríamos a un total de tres, al poder sumar desde ahora también los de Coria y Ahigal. El peso de la obra viaria augustea en la Lusitania parece equilibrarse así entre el eje Salamanca-Guarda y el eje sur-norte conformado por el iter ab Emerita Asturicam, algo que resulta completamente lógico en tanto que la propia Augusta Emerita, caput viae de este itinerario, fue también creación de Augusto ${ }^{58}$. La ausencia de una titulatura imperial completa en los miliarios de Ahigal y Coria -así como también en el de Casar de Cáceres- nos impide precisar una fecha concreta para esta primera medición oficial de la Vía de la Plata en época

56. Resulta evidente que, debido a la reciente fecha de publicación de esta pieza, ni Roldán (Iter) ni Puerta (en $M V P$ ) la pudieron recoger en sus respectivos catálogos de miliarios.

57. La inclusión que planteamos del miliario de Coria en la Vía de la Plata ahonda además en la extraordinaria importancia del iter ab Emerita Asturicam: en efecto, de cara a la elaboración del Corpus Miliariorum Lusitaniae (CML) y solo en territorio cacereño, llevamos contabilizados e identificados más de 130 miliarios en esta vía. Dicho de otro modo, pertenecen a esta ruta la práctica totalidad de los miliarios conocidos en la actual provincia cacereña, a excepción únicamente de los cuatro miliarios catalogados recientemente por Esteban Ortega con los n. ${ }^{\text {os }} 1350,1351,1373$ y 1425 en el quinto volumen, dedicado al territorio de Augustobriga, de su Corpus de Inscripciones Latinas de Cáceres (CILCc V).

58. Así es considerado de manera predominante en la investigación, si bien desde hace décadas se mantiene también la idea de la existencia de una fundación anterior a su constitución colonial por Augusto: véase en este sentido el ya clásico artículo de Canto, "Colonia», revisado y ampliado en sus conclusiones más recientemente en Canto, «Treinta años». 
augustea: aun sin poder descartar por completo una cronología paralela a la de los hitos de Fuenteguinaldo, Alfaiates o Argomil hacia el 23 a. C., lo cierto es que a la luz de los datos disponibles tal datación solo se basa en la difícilmente sustentable relación morfológica y textual con estos otros miliarios. Pero, en todo caso, a la luz de lo hasta aquí visto, parece claro que la consideración de dos nuevos miliarios augusteos en el iter ab Emerita Asturicam habrá de conllevar una reevaluación del protagonismo que tuvo el que fuera el primer emperador en la vertebración viaria y territorial de la nueva provincia lusitana, con las implicaciones políticas, estratégicas y económicas que ello debió conllevar.

\section{Bibliografía}

Abascal Palazón, José Manuel. "Programas epigráficos augusteos en Hispania". Anales de Arqueología Cordobesa 7 (1996): 45-82.

$A E=$ L'Année Épigraphique. Revue des publications épigraphiques relatives à l'Antiquité romaine. París.

Alarcão, José de. O dominio romano em Portugal. Lisboa: Mem Martins, 1988.

Canto, Alicia M. ${ }^{2}$. "Colonia Iulia Augusta Emerita: consideraciones en torno a su fundación y territorio». Gerión 7 (1989): 149-206.

Canto, Alicia M. ${ }^{a}$. «Treinta años de reflexiones sobre la Emerita cesariana: De lo que Dion Casio nunca dijo, a la alineación astronómica de la ciudad y los auspicia de César». En Lusitania Romana: del pasado al presente de la investigación. Actas de la IX Mesa Redonda de Lusitania (Madrid, 29-30 septiembre 2016), editado por Trinidad Nogales Basarrate, 341-391. Mérida: Museo Nacional de Arte Romano, 2017.

Castro, M. ${ }^{a}$ del Rosario y Alejandro Valiente. "Un nuevo miliario inédito de Domiciano perteneciente a la calzada de la Plata». En XIV Jornada de Historia de Fuente de Cantos: La vía de la Plata y otros estudios sobre Extremadura, editado por Felipe Lorenzana de la Puente y Rogelio Segovia Sopo, 67-79. Fuente de Cantos: Asociación Cultural Lucerna, 2013.

CIL II = Hübner, Emil. Corpus Inscriptionum Latinarum II. Inscriptiones Hispaniae Latinae. Berlín, 1869; Inscriptionum Hispaniae Latinarum Supplementum. Berlín, 1892.

CIL XVII/1 = Schmidt, Manfred G. y Camilla Campedelli, eds. Corpus Inscriptionum Latinarum XVII. Miliaria Imperii Romani. Pars prima: Provinciarum Hispaniae et Britaniae. Fasciculus primus: Miliaria Provinciae Hispaniae Citerioris. Berlín: Berlin-Brandenburgische Akademie der Wissenschaften, 2015. 
CILCc III = Esteban Ortega, Julio. Corpus de Inscripciones Latinas de Cáceres

Vol. III: Capera. Cáceres: Universidad de Extremadura, 2013.

CILCc IV = Esteban Ortega, Julio. Corpus de Inscripciones Latinas de Cáceres .

Vol. IV: Caurium. Cáceres: Universidad de Extremadura, 2017.

CILCC V = Esteban Ortega, Julio. Corpus de Inscripciones Latinas de Cáceres.

Vol. V: Augustobriga. Cáceres: Universidad de Extremadura, 2019.

CPILC $=$ Hurtado de San Antonio, Ricardo. Corpus Provincial de Inscripciones

Latinas de Cáceres. Cáceres: Diputación Provincial - Servicios Culturales, 1977.

$C R C=$ Río-Miranda, Jaime. La Ciudad Romana de Cáparra. Municipium Flavium Caparense. Pamplona: Ulzama Ediciones, 2010.

Curado, Fernando Patrício. "Notas sobre dois marcos miliários prismáticos, de Augusto (23 a.C.), da região da Guarda». Sabucale 5 (2013): 59-74.

EDCS = Epigraphik-Datenbank Clauss/Slaby: Manfred Clauss / Anne Kolb /

Wolfgang A. Slaby / Barbara Woitas (http://db.edcs.eu/epigr/epi.php?s_ sprache $=$ de).

Encarnação, José d'. «Augusto e a Lusitânia Ocidental: uma nótula». Studia Historica. Historia Antigua 32 (2014): 204-205.

ERPSa = Hernández Guerra, Liborio. Epigrafía de época romana de la provincia de Salamanca. Valladolid: Centro Buendía - Universidad de Valladolid, 2001.

FE 130: 547 = Esteban Ortega, Julio. "Miliario de Constantino I - Tejeda de Tiétar (Cáceres)». Ficheiro Epigráfico 130 (2015): n. ${ }^{\circ} 547$.

Griñó Frontera, Beatriz de. La Vía de la Plata. Mérida: Junta de Extremadura.

Consejería de Cultura y Patrimonio. Dirección General de Patrimonio Cultural, 1997 (trabajo inédito).

HEp = Hispania Epigraphica. Archivo Epigráfico de Hispania. Madrid: Universidad Complutense, 1989-actualidad.

HEDOL = Hispania Epigraphica On-line (http://eda-bea.es/pub/search_ select.php).

ILC = Sánchez Albalá, José Ignacio y Diego Vinagre Nevado. Corpus de las Inscripciones Latinas de Coria. Coria: Ayuntamiento de Coria, 1998.

$I R C P=$ Encarnação, José d'. Inscrições Romanas do Conventus Pacensis. Coimbra: Faculdade de Letras - Instituto de Arqueologia de Coimbra, 1984.

Lambrino, Scarlat. "Les inscriptions latines inédites du Musée Leite de Vasconcelos». O Arqueólogo Português. Série II 3 (1956): 5-73.

Mantas, Vasco Gil. "As cidades marítimas da Lusitania». En Les villes de Lusitanie romaine: biérarchies et territoires. Table ronde internationale du CNRS (Talence, le 8-9 décembre 1988), editado por Jean-Gerard Gorges, 149-205. París: Éditions du CNRS, 1990. 
Mantas, Vasco Gil. "A cidade luso-romana de Ossonoba». En Actas del I Coloquio de Historia Antigua de Andalucía (Córdoba, 1988), editado por Juan Francisco Rodríguez Neila, 515-537. Córdoba: Publicaciones Monte de Piedad y Caja de Ahorros de Córdoba, 1993.

Mantas, Vasco Gil. "As civitates: esboço da geografia política e económica do Algarve romano". En Noventa séculos entre a Serra e o Mar, editado por Maria Filomena Barata y Rui Parreira, 283-309. Lisboa: Instituto Português do Património Arquitectónico, 1997.

Mantas, Vasco Gil. "O espaço urbano nas cidades do norte da Lusitânia». En Los orígenes de la ciudad en el Noroeste hispánico: Actas del Congreso Internacional (Lugo, 15-18 de mayo de 1996). Vol. I, editado por Antonio Rodríguez Colmenero, 355-392. Lugo: Diputación de Lugo, 1998.

Mantas, Vasco Gil. "Recensão a J. I. Sánchez Albalá y D. Vinagre Nevado 1998: Corpus de Inscripciones Latinas de Coria». Conimbriga 41 (2002): 280-286.

Mantas, Vasco Gil. As vias romanas da Lusitânia. Mérida: Museo Nacional de Arte Romano, 2012.

Mantas, Vasco Gil. "Red viaria y red urbana en la Lusitania imperial». En Lusitania Romana. Origen de dos pueblos - Lusitania Romana. Origem de dois povos, editado por José M. álvarez Martínez, António Carvalho y Carlos Fabião, 109-118. Mérida: Museo Nacional de Arte Romano, 2015.

Mantas, Vasco Gil. "A política viária de Augusto na Lusitânia». En La fundación de Augusta Emerita y los orígenes de Lusitania, editado por Trinidad Nogales Basarrate y Nova Barrero Martín, 189-221. Mérida: Museo Nacional de Arte Romano, 2018

Mantas, Vasco Gil. "Da capital da Lusitânia a Bracara Augusta pela Serra da Estrela». Conimbriga 58 (2019): 255-300.

MVP = Puerta, Carmen. Los miliarios de la Vía de la Plata. Tesis doctoral inédita. Madrid. Universidad Complutense de Madrid, 1995.

Nogales Basarrate, Trinidad y Nova Barrero Martín, eds. La fundación de Augusta Emerita y los orígenes de Lusitania. Mérida: Museo Nacional de Arte Romano, 2018.

Osório, Marcos. O povoamento romano do Alto Côa. Guarda: Câmara Municipal de Guarda, 2006.

Perestrelo, Manuel Sabino G. A romanização na bacia do rio Côa. Lisboa: Parque Arqueológico Vale do Côa, 2003.

RAP = Garcia, José Manuel. Religiões Antigas de Portugal. Aditamentos e observações as "Religiões da Lusitânia" de J. Leite de Vasconcelos. Fontes epigráficas. Lisboa: Imprensa Nacional - Casa da Moeda, 1991.

Redentor, Armando y Pedro C. Carvalho. "Continuidade e mudança no Norte da Lusitânia no tempo de Augusto». Gerión 35/2 (2017): 417-441. 
Río-Miranda, Jaime. "Nuevas aportaciones a la epigrafía y arqueología romana de Cáceres. Miliarios inéditos en la Calzada de la Plata término de Ahigal». Ahigal 3 (2000): 4-6 (= http://www.caparra.es/archivospdf/03-2000.pdf).

Río-Miranda, Jaime y M. ${ }^{a}$ Gabriela Iglesias. "Nuevas lecturas a la epigrafía de la provincia de Cáceres». Boletín Informativo del Grupo Cultural de Valdeobispo 7 (1999): 1-5 (= https://www.academia.edu/10372692/ RIO_MIRANDA_J_IGLESIAS_Ma_Ga_Nuevas_lecturas_a_la_epigraf\%C3\%ADa_de_C\%C3\%A1ceres).

Río-Miranda, Jaime y M. ${ }^{a}$ Gabriela Iglesias. "Nuevas lecturas a la epigrafía de la provincia de Cáceres». Abigal 22 (2005): s.p. (= http://www.caparra. es/archivospdf/22-2005.pdf).

Rodríguez Colmenero, Antonio y Santiago Ferrer Sierra. "Por tierras de León y Zamora. Nuevas inscripciones y reinterpretación de otras». Larouco 3 (2001): 237-242.

Roldán, José Manuel. Iter ab Emerita Asturicam: El Camino de la Plata. Salamanca: Universidad de Salamanca - Facultad de Filosofía y Letras, 1971.

Roldán, José Manuel. "El Camino de la Plata: estado de la cuestión». Anas 18 (2005): 11-27.

Salinas, Manuel. «El impacto de la romanización augustea en la cuenca del Duero». Gerión 35/2 (2017): 599-622.

Salinas, Manuel y Juan José Palao. "Nuevo miliario de Augusto procedente de Fuenteguinaldo (Salamanca)». Archivo Español de Arqueología 85 (2012): 273-279.

Saquete Chamizo, José Carlos. "Aspectos políticos, estratégicos y económicos en la fundación de Augusta Emerita». En El yacimiento emeritense: 1910-2010. Actas del Congreso Internacional, editado por José M. ${ }^{a}$ Álvarez Martínez y Pedro Mateos Cruz, 111-126. Mérida: Ayuntamiento de Mérida, 2011.

Torres y Tapia, Alonso de. Crónica de la Orden de Alcántara. Tomo I. Madrid, 1743.

Vaz, João Luís Inês. "Inscrição romana de Argomil (Pinhel)». Beira Alta 44/4 (1985): 635-639.

Vaz, João Luís Inês. "Linhas urbanísticas de Viseu na época romana». En Los orígenes de la ciudad en el Noroeste hispánico: Actas del Congreso Internacional (Lugo, 15-18 de mayo de 1996). Vol. I, editado por Antonio Rodríguez Colmenero, 393-407. Lugo: Diputación de Lugo, 1998. 